\title{
Odonto-onycho-dermal dysplasia in a patient homozygous for a WNT10A nonsense mutation and mild manifestations of ectodermal dysplasia in carriers of the mutation
}

\author{
Anne Bruun Krøigård ${ }^{1,2^{*}}$, Ole Clemmensen², Hans Gjørup ${ }^{3}$, Jens Michael Hertz ${ }^{1,4}$ and Anette Bygum ${ }^{4,5}$
}

\begin{abstract}
Background: Odonto-onycho-dermal dysplasia (OODD) is a rare form of ectodermal dysplasia characterized by severe oligodontia, onychodysplasia, palmoplantar hyperkeratosis, dry skin, hypotrichosis, and hyperhidrosis of the palms and soles. The ectodermal dysplasias resulting from biallelic mutations in the WNT10A gene result in highly variable phenotypes, ranging from isolated tooth agenesis to OODD and Schöpf-Schulz-Passarge syndrome (SSPS).

Case presentation: We identified a female patient, with consanguineous parents, who was clinically diagnosed with OODD. Genetic testing showed that she was homozygous for a previously reported pathogenic mutation in the WNT10A gene, c.321C > A, p.Cys107*. The skin and nail abnormalities were for many years interpreted as psoriasis and treated accordingly. A thorough clinical examination revealed hypotrichosis and hyperhidrosis of the soles and dental examination revealed agenesis of permanent teeth except the two maxillary central incisors. Skin biopsies from the hyperkeratotic palms and soles showed the characteristic changes of eccrine syringofibroadenomatosis, which has been described in patients with ectodermal dysplasias. Together with a family history of tooth anomalies, this lead to the clinical suspicion of a hereditary ectodermal dysplasia.
\end{abstract}

Conclusion: This case illustrates the challenges of diagnosing ectodermal dysplasia like OODD and highlights the relevance of interdisciplinary cooperation in the diagnosis of rare conditions.

Keywords: Odonto-onycho-dermal dysplasia, OODD, Ectodermal dysplasia, WNT10A gene, Oligodontia

\section{Background}

Odonto-onycho-dermal dysplasia (OODD) (OMIM\# 257980) [1], is a rare autosomal recessive inherited form of ectodermal dysplasia, first reported in 1983 [2] and later further delineated by others [3-7]. The phenotypic appearance includes severe oligodontia, onychodysplasia, palmoplantar hyperkeratosis, dry skin, hypotrichosis, and hyperhidrosis of the palms and soles. A smooth tongue with marked reduction

\footnotetext{
* Correspondence: anne.kroeigaard@rsyd.dk

${ }^{1}$ Department of Clinical Genetics, Odense University Hospital, Sdr. Boulevard 29, DK-5000 Odense, Denmark

2Department of Clinical Pathology, Odense University Hospital, Odense, Denmark

Full list of author information is available at the end of the article
}

of fungiform and filiform papillae has also been reported [4].

OODD is caused by biallelic mutations in the WNT10A gene. WNT10A is a member of the WNT gene family, and is found to activate the canonical Wnt pathway, a signal transduction pathway essential for development of tissues of ectodermal origin [8]. Mutations in the WNT10A gene cause a broad spectrum of ectodermal dysplasias, ranging from mild signs of ectodermal dysplasia such as hypodontia to syndromes like OODD and Schöpf-Schulz-Passarge syndrome (SSPS). The clinical phenotype of SSPS includes numerous cysts along the eyelid margins in addition to palmoplantar keratoderma, hair, nail and teeth abnormalities [9]. Wnt10A 
has been recognized as a key regulator of odontogenesis and is found to be involved in regulation of odontoblast differentiation [10]. This is in line with recent evidence that WNT10A mutations are a common cause of nonsyndromic tooth agenesis [11, 12].

According to the Human Gene Mutation Database, 66 different mutations in the WNT10A gene have been reported, of which 58 are missense and nonsense mutations [13]. Until now only around 30 patients with OODD have been reported in the literature $[2,4-7,14-17]$. However, the exact figure is difficult to estimate due to a lack of clear phenotypic distinction between the ectodermal dysplasias. Our report on a case of OODD emphasizes the challenges of diagnosing rare conditions like OODD. The condition is probably underreported, since a causal relation between skin, nail, hair and teeth abnormalities is needed in order to suspect the diagnosis.

\section{Case presentation}

The female patient, now aged 75, had since early childhood been affected by skin, tooth and nail abnormalities, but was only recently diagnosed with OODD. From early life she developed a blistering erythema and thick scaling on palms and soles (Fig. 1). She had dry skin, slightly dystrophic and brittle finger and toe nails with spooning. She reported abnormal sweating on the feet, which aggravated blistering of the skin. Since adolescence she reported hypotrichosis and in adulthood developed a bald patch on the scalp. She showed erythematous plaques on both cheeks and the nose and had two facial basal cell carcinomas surgically removed. At the time of our examinations, she had many of her deciduous teeth (six molars, four canines, and one mandibular incisor). Only two permanent teeth were present (maxillary incisors), and they were screwdrivershaped. According to the patient's memory, only one tooth had been extracted. Through adulthood deciduous teeth were maintained and supplemented by removable dentures (Fig. 2). At present, the prognosis of three of the molars is very poor.

Until the age of 75 , the causal relation between these symptoms was not recognized and the skin and nail manifestations were interpreted as psoriasis and treated accordingly. Skin biopsies from the palms and soles showed an acrosyringial proliferation of anastomosing, epithelial cords and strands extending from the epidermis into a fibrovascular stroma. The epithelial cells were small and uniform, and disclosed a ductal differentiation focally. These findings correspond to those described for eccrine syringofibroadenomatosis (ESFA).

\section{Genetics}

Genomic DNA purified from a blood sample from the patient was analyzed at All Wales Molecular Genetics Laboratory, Institute of Medical Genetics, UK using bidirectional Sanger sequencing of the WNT10A gene. The patient was homozygous for a nonsense mutation in the WNT10A gene, c.321C > A, p.Cys107*.
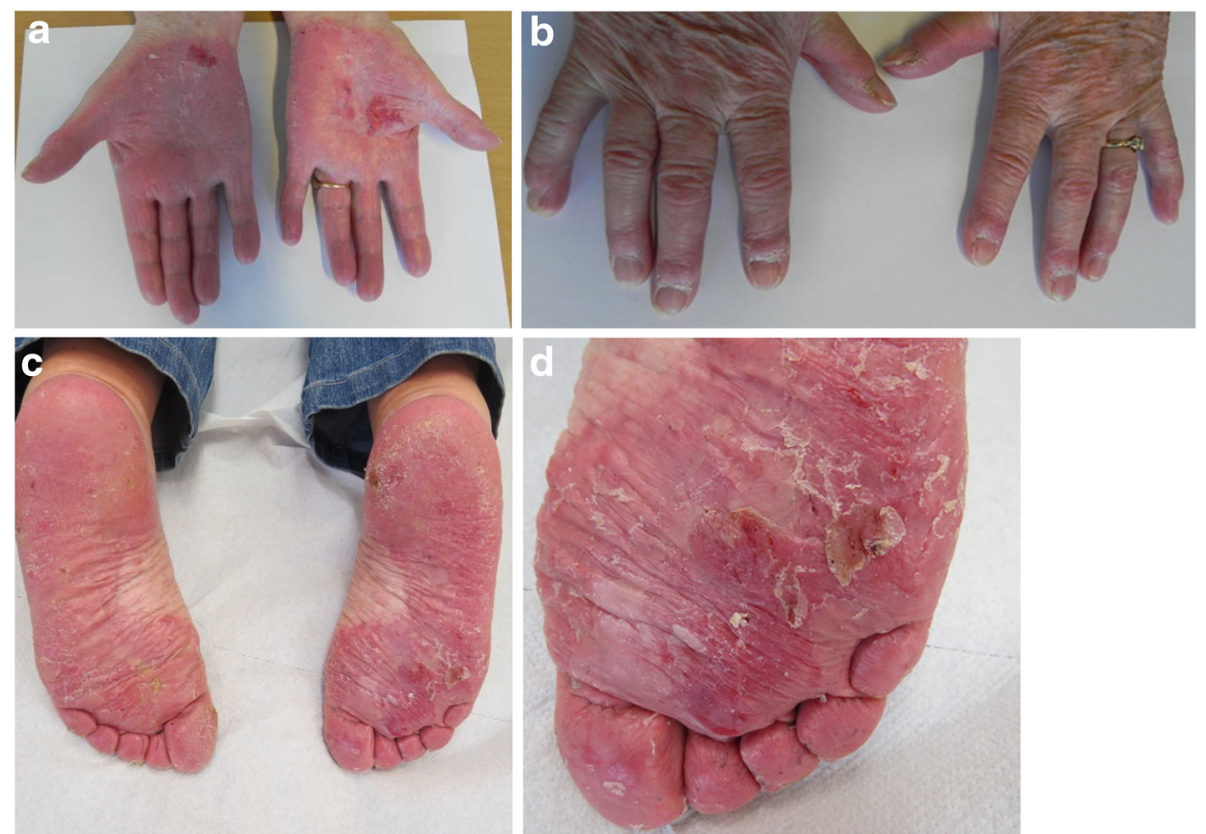

Fig. 1 Upper panel: Hyperkeratosis of the palms with erythema, scaling, erosions and fissuring. Dystrophic finger nails with spooning. Lower panel: Hyperkeratosis of the soles with erythema, scaling, erosions and fissuring 

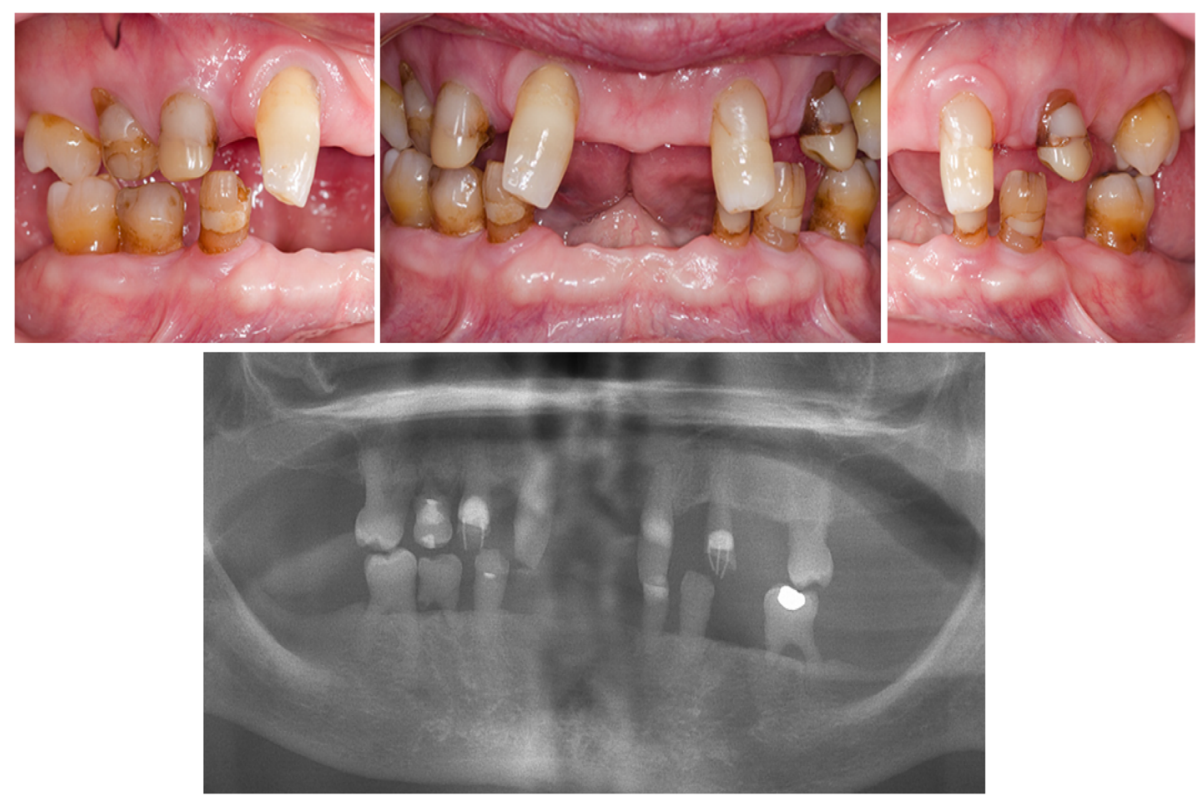

Fig. 2 Upper panel: Intraoral photos of natural teeth in occlusion. Lower panel: Panoramic radiograph of the dentition. Preserved decidious dentition (11 decidious teeth), two screwdriver-shaped permanent incisors, and a large diastema mediale. Agenesis of all permanent teeth except two

\section{Family history}

The family history revealed consanguinity as the parents were first cousins, in accordance with autosomal recessive inheritance (Fig. 3). The patient's brother had a phenotypic presentation compatible with severe OODD, but was never clinically diagnosed with the syndrome and genetic testing was never performed.

The patient's father had small, conical teeth, most likely deciduous teeth, and had artificial dentition in adult life. He had no other symptoms and thus, presented with isolated tooth agenesis. Genetic testing was never performed. The patient's mother, also an obligate carrier of the mutation, was completely asymptomatic. It is not known whether the patient's grandparents had any symptoms. The patient's nephews also presented with tooth agenesis and thin hair. Genetic testing was not performed, but it is speculated that they were heterozygous for the WNT10A mutation.

\section{Discussion}

We present a female case of OODD homozygous for c.321C > A, p.Cys107* in WNT10A, which is a previously reported pathogenic mutation. In another family affected by ectodermal dysplasia, a male patient homozygous for

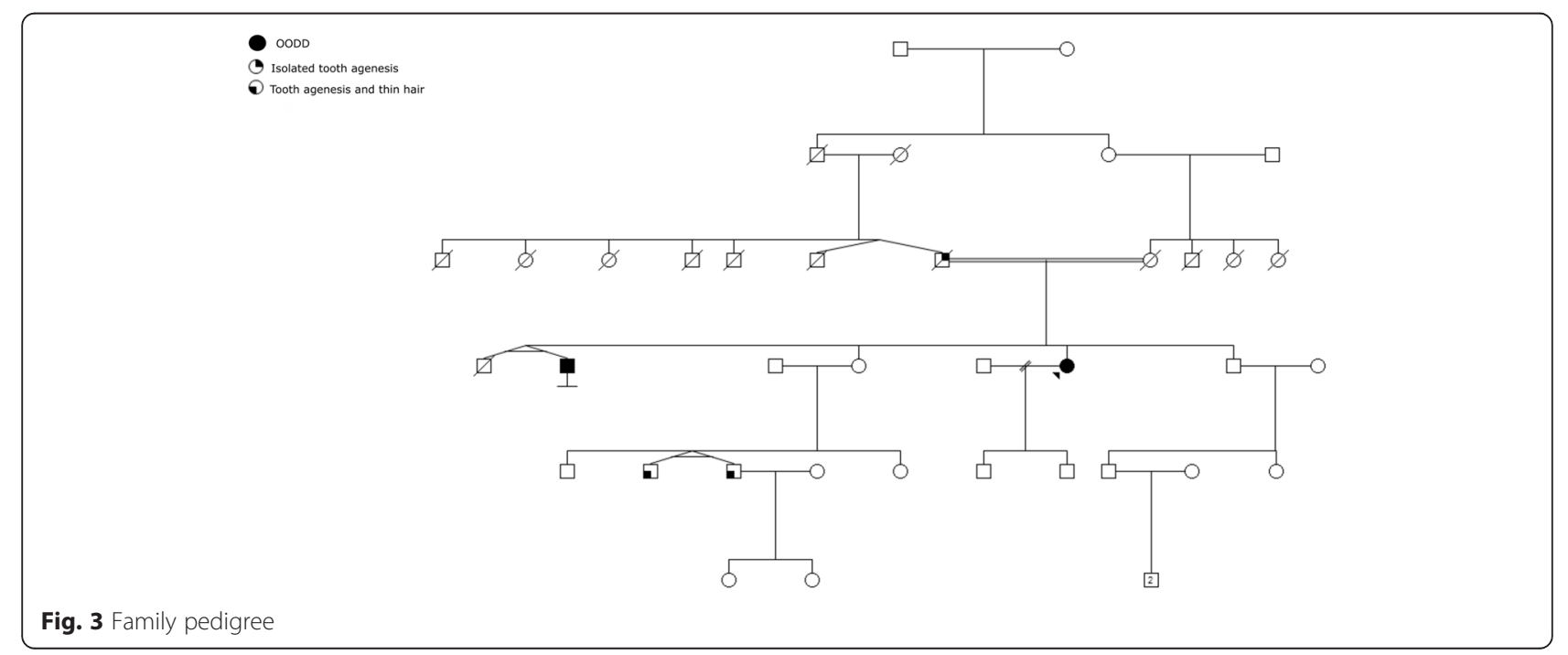


the exact same mutation had clinical features of SSPS, whereas individuals who were compound heterozygous for p.Cys $107 \%$ p.Phe228Ile displayed a phenotype akin to OODD [18]. This illustrates lack of a clear genotypephenotype correlation in these conditions.

The c.321C > A, p.Cys107* reported here, is previously reported in nine patients clinically diagnosed with OODD $[14,16,18,19]$, one patient with oligodontia and maxillary bone hypoplasia [20], 17 patients with isolated tooth agenesis $[11,21]$ and in nine patients with SSPS $[9,16,18,19]$. The mutation is seen in both homozygous and compound heterozygous state and homozygous individuals are generally more severely affected than compound heterozygous individuals. This is not surprising, as c. $321 \mathrm{C}>\mathrm{A}$, p.Cys $107^{*}$ is predicted to result in premature termination of the sequence which may lead to nonsense-mediated decay of the mRNA, whereas missense mutations most likely affect protein function to a lesser extent. As the clinical presentation of patients with the same genotype ranges from mild symptoms of ectodermal dysplasia to more severe syndromic manifestations, it is recently concluded that OODD and SSPS should be considered as variable expression of the same WNT10A genotype [19].

Our patient presented with two basal cell carcinomas prior to being diagnosed with OODD. Basal cell carcinomas have been described in other patients with OODD and an increased skin tumor risk in these patients has been suggested [16]. However, the presence may be coincidental as basal cell carcinoma occurs in $14 \%$ of elderly people [22].

The fact that the patient's father and nephews presented with tooth agenesis and tooth agenesis and thin hair, respectively, is in line with observations that heterozygous carriers may display minor disease-associated symptoms. It has been reported that about $50 \%$ of individuals heterozygous for mutations in WNT10A display a phenotypic manifestation of abnormal Wnt signaling, such as abnormal shape or agenesis of one or several permanent teeth, nail dystrophy, dry skin, palmoplantar hyperkeratosis, sparse scalp hair, sparse eyelashes or sparse eyebrows [16]. In isolated oligodontia, a great proportion (up to $54 \%$ ) of the cases are associated by WNT10A mutations [23, 24]. In a population-based study on patients with oligodontia, WNT10A mutations accounted for $25 \%$ of the cases, and it was shown that all biallelic WNT10A mutations were associated with absence of maxillary and mandibular molars as well as mandibular central incisors but presence of maxillary central incisors [23]. This is in accordance with the dental phenotype of the present OODD-case. A tendency of sex-biased manifestation pattern was reported in heterozygous individuals with a slightly higher proportion of tooth anomalies in males compared to females, which may implicate gender-specific differences in WNT10A expression [16].

Eccrine syringofibroadenoma is a rare, benign adnexal tumor histopathologically characterized by proliferation of anastomosing cords and strands of basaloid acrosyringeal cells, ductal differentiation and a mucinous fibrovascular stroma. Identical histopathological changes are seen in the diffuse variant (ESFA), which characteristically is located at the acral skin of palms and soles [25]. ESFA has been described in association with ectodermal dysplasia, unspecified as well as specified (SSPS), and in a review of 44 patients with eccrine syringofibroadenoma, ten patients among 17 with multiple or diffuse ESFA fulfilled the clinical criteria of SSPS [26]. This suggested that our patient should be examined for ectodermal dysplasia.

\section{Conclusion}

We present a female patient diagnosed with OODD, which is a rare autosomal recessive inherited form of ectodermal dysplasia. The patient's skin and nail manifestations were for many years interpreted as psoriasis and treated accordingly. This highlights the importance of including the full clinical picture comprising dental examination, histopathological examination and family history in order to establish the diagnosis of rare conditions like SSPS and OODD.

\section{Consent}

Written informed consent was obtained from the patient for publication of this Case report and any accompanying images. A copy of the written consent is available for review by the Editor of this journal.

\section{Abbreviations}

OODD: odonto-onycho-dermal dysplasia; SSPS: Schöpf-Schulz-Passarge syndrome; ESFA: eccrine syringofibroadenomatosis.

\section{Competing interests \\ The authors declare that they have no competing interests.}

\section{Authors' contributions}

$A B$ was the treating physician and performed the clinical evaluation. $H G$ performed the dental evaluation and description. OC was the pathologist on the case and performed the histopathological examination of skin biopsies. $\mathrm{ABK}$ and $\mathrm{JMH}$ were responsible for genetic testing and genetic counselling. ABK wrote the manuscript. All authors read and approved the final manuscript.

\section{Acknowledgements}

The authors thank the patient and her family for participating in the study.

\section{Author details}

'Department of Clinical Genetics, Odense University Hospital, Sdr. Boulevard 29, DK-5000 Odense, Denmark. ${ }^{2}$ Department of Clinical Pathology, Odense University Hospital, Odense, Denmark. ${ }^{3}$ Department of Maxillofacial Surgery, Center for Oral Health in Rare Diseases, Aarhus University Hospital, Aarhus, Denmark. ${ }^{4}$ Department of Clinical Research, University of Southern Denmark, Odense, Denmark. ${ }^{5}$ Department of Dermatology and Allergy Centre, Odense University Hospital, Odense, Denmark. 
Received: 19 November 2015 Accepted: 4 March 2016

Published online: 10 March 2016

\section{References}

1. Online Mendelian Inheritance in Man. Odonto-onycho-dermal dysplasia (OODD) OMIM\# 257980 [http://www.omim.org/entry/257980]

2. Fadhil M, Ghabra TA, Deeb M, Der Kaloustian VM. Odontoonychodermal dysplasia: a previously apparently undescribed ectodermal dysplasia. Am J Med Genet. 1983;14:335-46.

3. Arnold WP, Merkx MA, Steijlen PM. Variant of odontoonychodermal dysplasia? Am J Med Genet. 1995;59:242-4.

4. Adaimy L, Chouery E, Megarbane H, Mroueh S, Delague V, Nicolas E, Belguith $\mathrm{H}$, de Mazancourt $\mathrm{P}$, Megarbane A. Mutation in WNT10A is associated with an autosomal recessive ectodermal dysplasia: the odonto-onycho-dermal dysplasia. Am J Hum Genet. 2007:81:821-8.

5. Zirbel GM, Ruttum MS, Post AC, Esterly NB. Odonto-onycho-dermal dysplasia. Br J Dermatol. 1995;133:797-800.

6. Mégarbané $H$, Haddad M, Delague V, Renoux J, Boehm N, Mégarbané A. Further delineation of the odonto-onycho-dermal dysplasia syndrome. Am J Med Genet A. 2004:129A:193-7.

7. Adams BB. Odonto-onycho-dermal dysplasia syndrome. J Am Acad Dermatol. 2007:57:732-3.

8. Mues G, Bonds J, Xiang L, Vieira AR, Seymen F, Klein O, D'Souza RN. The WNT10A gene in Ectodermal Dysplasias and Selective Tooth Agenesis. Am J Med Genet A. 2014;164:2455-60.

9. Tziotzios C, Petrof G, Liu L, Verma A, Wedgeworth EK, Mellerio JE, McGrath JA. Clinical features and WNT10A mutations in seven unrelated cases of Schöpf-Schulz-Passarge syndrome. Br J Dermatol. 2014;171:1211-4.

10. Yamashiro T, Zheng L, Shitaku Y, Saito M, Tsubakimoto T, Takada K, TakanoYamamoto T, Thesleff I. Wnt10a regulates dentin sialophosphoprotein mRNA expression and possibly links odontoblast differentiation and tooth morphogenesis. Differ Res Biol Divers. 2007;75:452-62.

11. Mostowska A, Biedziak B, Zadurska M, Dunin-Wilczynska I, Lianeri M, Jagodzinski P. Nucleotide variants of genes encoding components of the Wnt signalling pathway and the risk of non-syndromic tooth agenesis. Clin Genet. 2013;84:429-40

12. Song $\mathrm{S}$, Zhao $\mathrm{R}$, He H, Zhang J, Feng H, Lin L. WNT10A variants are associated with non-syndromic tooth agenesis in the general population. Hum Genet. 2014;133:117-24.

13. Stenson PD, Mort M, Ball EV, Shaw K, Phillips A, Cooper DN. The Human Gene Mutation Database: building a comprehensive mutation repository for clinical and molecular genetics, diagnostic testing and personalized genomic medicine. Hum Genet. 2014;133:1-9.

14. Van Geel M, Gattas M, Kesler Y, Tong P, Yan H, Tran K, Steijlen PM, Murrell DF, Van Steensel MM. Phenotypic variability associated with WNT10A nonsense mutations. Br J Dermatol. 2010;162:1403-6.

15. Nawaz S, Klar J, Wajid M, Aslam M, Tariq M, Schuster J, Baig SM, Dahl N. WNT10A missense mutation associated with a complete Odonto-OnychoDermal Dysplasia syndrome. Eur J Hum Genet. 2009;17:1600-5.

16. Bohring A, Stamm T, Spaich C, Haase C, Spree K, Hehr U, Hoffmann M, Ledig S, Sel S, Wieacker P, Röpke A. WNT10A mutations are a frequent cause of a broad spectrum of ectodermal dysplasias with sex-biased manifestation pattern in heterozygotes. Am J Hum Genet. 2009;85:97-105.

17. Kantaputra P, Kaewgahya M, Jotikasthira D, Kantaputra W. Tricho-odontoonycho-dermal dysplasia and WNT10A mutations. Am J Med Genet A 2014;164:1041-8.

18. Wedgeworth EK, Nagy N, White JML, Pembroke AC, McGrath JA. Intrafamilial variability of ectodermal defects associated with WNT10A mutations. Acta Derm Venereol. 2011:91:346-7.

19. Vink CP, Ockeloen CW, ten Kate S, Koolen DA, Ploos van Amstel JK, Kuijpers-Jagtman A-M, van Heumen CC, Kleefstra T, Carels CEL. Variability in dentofacial phenotypes in four families with WNT10A mutations. Eur J Hum Genet. 2014;22:1063-70.

20. Clauss F, Waltmann E, Barriere $P$, Hadj-Rabia S, Manière M-C, Schmittbuhl M. Dento-maxillo-facial phenotype and implants-based oral rehabilitation in Ectodermal Dysplasia with WNT10A gene mutation: Report of a case and literature review. J Cranio-Maxillofac Surg. 2014;42:e346-51.

21. Yang J, Wang S-K, Choi M, Reid BM, Hu Y, Lee Y-L, Herzog CR, Kim-Berman H, Lee M, Benke PJ, Kent Lloyd KC, Simmer JP, Hu JC-C. Taurodontism, variations in tooth number, and misshapened crowns in Wnt10a null mice and human kindreds. Mol Genet Genomic Med. 2015;3:40-58.
22. Deo MS, Kerse N, Vandal AC, Jarrett P. Dermatological disease in the older age group: a cross-sectional study in aged care facilities. BMJ Open. 2015;5:e009941.

23. Arzoo PS, Klar J, Bergendal B, Norderyd J, Dahl N. WNT10A mutations account for $1 / 4$ of population-based isolated oligodontia and show phenotypic correlations. Am J Med Genet A. 2014;164A:353-9.

24. van den Boogaard $M-J$, Créton $M$, Bronkhorst $Y$, van der Hout $A$, Hennekam E, Lindhout D, Cune M, Ploos van Amstel HK. Mutations in WNT10A are present in more than half of isolated hypodontia cases. J Med Genet. 2012; 49:327-31.

25. Lui H, Stewart WD, English JC, Wood WS. Eccrine syringofibroadenomatosis: a clinical and histologic study and review of the literature. J Am Acad Dermatol. 1992;26(5 Pt 2):805-13.

26. Starink TM. Eccrine syringofibroadenoma: multiple lesions representing a new cutaneous marker of the Schöpf syndrome, and solitary nonhereditary tumors. J Am Acad Dermatol. 1997:36:569-76.

\section{Submit your next manuscript to BioMed Central and we will help you at every step:}

- We accept pre-submission inquiries

- Our selector tool helps you to find the most relevant journal

- We provide round the clock customer support

- Convenient online submission

- Thorough peer review

- Inclusion in PubMed and all major indexing services

- Maximum visibility for your research

Submit your manuscript at www.biomedcentral.com/submit
) Biomed Central 